COMPÓSITOS DE PEAD/DIATOMITA MODIFICADA COM
GRUPOS METILSILANO: ANÁLISE DAS PROPRIEDADES
TÉRMICAS E MECÂNICAS

\title{
HDPE/METHYLSILANE MODIFIED DIATOMITE COMPOSITES: ANALYSIS OF THERMAL AND MECHANICAL PROPERTIES
}

\author{
FENSTERSEIFER, Camila Rivaldo"; BRAMBILLA, Rodrigo²*; \\ 1,2 Universidade do Vale do Rio dos Sinos, Escola Politécnica, Av Unisinos, 950, cep 93020-190, \\ São Leopoldo - RS, Brasil.
}

Braskem S.A., Inovação e Tecnologia, Área de Catálise, Via Oeste, Lote 5, cep 95853-000, Triunfo - RS, Brasil. (fone: +555137218140 )

* Autor correspondente

e-mail: rodrigo.brambilla@braskem.com

Received 01 August 2018; received in revised form 30 August 2018; accepted 22 September 2018

\section{RESUMO}

Devido à grande demanda de novos materiais para as aplicações atuais do mercado, existem vários tipos de materiais compósitos. Um exemplo, é o polietileno de alta densidade (PEAD) reforçado com partículas de sílica. A diatomita é um tipo de sílica natural, comumente utilizada em meios filtrantes. No presente trabalho, a diatomita foi organofuncionalizada com o metiltrietóxisilano (C1) e utilizada, em teores mássicos de 2,0 e $5,0 \%$, na preparação de compósitos com matriz de PEAD, através do método de extrusão. A diatomita e os compósitos foram caracterizados por diferentes técnicas complementares de caracterização, a saber: espectroscopia no infravermelho por transformada de Fourier (FTIR), porosimetria de adsorção-dessorção de $\mathrm{N}_{2}$, granulometria por difração a laser, análise termogravimétrica (TGA), microscopia eletrônica de varredura (SEM) e calorimetria diferencial exploratória (DSC). Os compósitos foram avaliados em termos de propriedades mecânicas por: análise dinâmico-mecânica (DMTA), ensaio de impacto Izod e ensaios de resistência à flexão e à tração. $\mathrm{O}$ espectro de FTIR da diatomita organofuncionalizada apresentou bandas características de grupos metila, comprovando a eficiência da modificação de superfície. A adição de 5,0 \% de diatomita no PEAD resultou em um aumento de $8,0^{\circ} \mathrm{C}$ na estabilidade térmica, na cristalinidade (72 para $78 \%$ e em, aproximadamente, 4,0 \% no módulo de armazenamento (G'), em comparação ao PEAD puro. As análises de SEM evidenciaram a presença de aglomerados de diatomita na matriz de PEAD. A resistência ao impacto Izod dos compósitos para esse compósito foi de $50 \mathrm{~J} / \mathrm{m}$, metade do valor medido para o PEAD puro. As propriedades de resistência à tração não foram influenciadas pela presença de diatomita no PEAD.

Palavras-chave: polietileno, diatomácea, sílica, organofuncionalização, organosilano.

\section{ABSTRACT}

According to IUPAC, the composites are multicomponent materials comprising multiple, different (nongaseous) phase domains in which at least one type of phase domain is a continuous phase.High density polyethylene (HDPE) reinforced with silica particles is an example of a composite material. Diatomite is a natural silica commonly used in filter media.In the present work, the diatomite was organofunctionalized with methyltriethoxysilane $(\mathrm{C} 1)$ and then used in the preparation of HDPE/diatomite composites with diatomite content of 2.0 and $5.0 \mathrm{wt} \%$. The composites were evaluated in terms of mechanical properties by dynamicmechanical analysis (DMTA), Izod impact test and flexural strength and tensile strength tests. TheFourier transform infrared spectrum (FTIR) of the organofunctionalized diatomite presented bands characteristic of methyl groups, proving the efficiency of the surface modification. The addition of $5.0 \%$ diatomite in HDPE resulted in an increase of $8.0{ }^{\circ} \mathrm{C}$ in thermal stability, crystallinity (72 to $78 \%$ ) and in approximately $4.0 \%$ in the storage modulus ( $\left.G^{\prime}\right)$, compared to pure HDPE.SEM analyzes showed the presence of diatomite agglomerates in the HDPE matrix. The Izod impact strength of the composites for this composite was $50 \mathrm{~J} / \mathrm{m}$, half of that observed for pure HDPE. The properties of tensile strength were not influenced by the presence of diatomite in HDPE. 


\section{INTRODUÇÃO}

Os materiais plásticos, devido ao seu alto desempenho em relação a outros materiais poliméricos, vêm sendo cada vez mais utilizados na sociedade atual, sendo aplicados em diversos segmentos, como na produção de embalagens, materiais de construção civil, aparelhos médicos,dentre tantas outras aplicações. (ABIPLAST, 2015). De acordo com a ABIPLAST (2015) a produção de plástico no mundo é de aproximadamente 260 milhões de toneladas.

Mesmo sendo utilizado em diversos segmentos, os polímeros termoplásticos podem ter suas propriedades modificadas através da junção com outros materiais, e com isso ampliar ainda mais as suas aplicações. (LIMA, 2007). Smith e Hashemi (2012, p. 8) definem compósitos como: "[...] dois ou mais materiais integrados de modo a formar um novo material. " Os materiais compósitos são formados pela matriz e por um material de reforço, usualmente chamado de carga. (SMITH e HASHEMI, 2012).

Existem vários tipos de materiais compósitos, porém os que utilizam como matriz os polímeros possuem vantagem devido seu baixo custo e facilidade relativa dos processos de fabricação. (VENTURA, 2009). Neste contexto, um exemplo de material compósito é o polietileno de alta densidade (PEAD) utilizando a sílica como reforço.

A sílica utilizada como material de reforço é de origem sintética, sendo assim, é um material que contém substâncias desenvolvidas em laboratório e não extraídas diretamente da natureza. Uma alternativa, seria utilizar uma sílica natural, como a diatomita. Segundo Luz e Lins (2005, p.399 apud BREESE, 1994): "A diatomita é uma matéria-prima mineral de origem sedimentar e biogênica, constituída a partir do acúmulo de carapaças de algas diatomáceas que foram se fossilizando, desde o período précambriano [...]".

A diatomita vem sendo utilizada na indústria em diversas áreas, como auxiliar de filtração, como carga funcional, como adsorvente, abrasivo ou isolante. (LUZ e LINS, 2005).

Embora sejam encontrados vários estudos na literatura envolvendo a utilização de sílicas como carga para o polietileno de alta densidade(PEAD), a diatomita ainda foi muito pouco explorada neste cenário.

Dessa forma, o presente estudo investigou as potencialidades e limitações da utilização de diatomita organofuncionalizada com grupos metilsilano como agente de reforço para o polietileno de alta densidade (PEAD).

$O$ presente trabalho teve por objetivos específicos: (i) avaliar o efeito da modificação com grupos metilsilano (C1) nas propriedades superficiais, texturais e morfológicas da diatomita; (ii) comparar as propriedades térmicas e mecânicas dos compósitos de PEAD-diatomita com as propriedades do PEAD puro e (iii) correlacionar o teor de diatomita (2,0 e 5,0\%) com as propriedades térmicas e mecânicas dos compósitos de PEAD/diatomita-C1 resultantes.

\section{PARTE EXPERIMENTAL}

\section{Materiais e reagentes}

Para a realização do trabalho foram utilizados os seguintes reagentes e solventes:

-Diatomita (Synth, utilizada após tratamento térmico e modificação com grupos metilsilano); -Metiltrietoxisilano (Sigma-Aldrich, $95 \%$ de pureza, utilizado sem purificação prévia);

-Hexano (Sigma-Aldrich, $95 \%$ de pureza, utilizado sem purificação prévia);

-Polietileno de alta densidade na forma de pó (Braskem, utilizado sem purificação prévia);

-Brometo de potássio (Sigma-Aldrich, grau FTIR, seco à $200^{\circ} \mathrm{C}$ por $8 \mathrm{~h}$ ).

\section{Organofuncionalização da diatomita}

Primeiramente, foi realizado um tratamento térmico na diatomita com o objetivo de eliminar a água adsorvida, e formar grupos silanóis $(\mathrm{OH})$ isolados, que são mais reativos, facilitando a ligação com o organosilano na reação de modificação. (BERGNA; ROBERTS, 2006). Para este procedimento, a diatomita foi transferida para um cadinho e em seguida colocada em um forno mufla a $200 \stackrel{\circ}{ } \mathrm{C}$ durante $12 \mathrm{~h}$ sob fluxo constante de nitrogênio. $O$ resfriamento da diatomita foi realizado em um dessecador.

Após o tratamento térmico, foi realizadaa modificação da diatomita através do método de enxerto (grafting), conforme 
adaptação do procedimento descrito por Zhuravlev (2000) e Brambilla et al. (2007). Em uma preparação típica, $200 \mathrm{~g}$ de diatomita foi colocada em um balão Schlenk através de uma câmara seca (para se evitar o contato com o ar atmosférico), e em seguida 0 balão foi transportado para uma capela. Em seguida, foi adicionado hexano no balão, através de uma cânula, de forma a propiciar total suspensão da diatomita nesse solvente orgânico. Após a adição de hexano, $30 \mathrm{~mL}$ de metiltrietoxisilano (200 $\mathrm{mmol}$ ) foi adicionado, através de uma seringa de vidro, ao balão contendo a diatomita suspensa. A quantidade desse reagente foi escolhida de acordo com o teor de organosilano comumente utilizado em sílicas organofuncionalizadas comerciais $(1,0 \mathrm{mmol}$ de silano/g de sílica). A adição do organosilano foi realizada na temperatura de $25^{\circ} \mathrm{C}$, sob agitação e fluxo de nitrogênio constantes. A reação foi mantida sob agitação, mantendo o balão fechado, por um período de $6 \mathrm{~h}$. Por último, o solvente foi removido sob fluxo de nitrogênio e a secagem completa da diatomita organofuncionalizada foi realizada em estufa a $120{ }^{\circ} \mathrm{C}$ por $12 \mathrm{~h}$.

Para facilitar a discussão dos resultados, a diatomita organofuncionalizada foi denominada de diatomita-C1.

\section{Caracterização da diatomita e diatomita-C1}

A diatomita in natura e a diatomita-C1 foram caracterizadas por uma série de técnicas complementares com os objetivos de avaliar suas propriedades de superfície, texturais e morfológicas. As técnicas de caracterização utilizadas foram: espectroscopia no infravermelho com transformada de Fourier (FTIR), porosimetria de adsorção-dessorção de $\mathrm{N}_{2}$, microscopia eletrônica de varredura (MEV) e granulometria por difração a laser. Os procedimentos, os equipamentos e condições de análise por cada uma dessas técnicas são descritos a seguir.

\section{Espectroscopia na região do infravermelho com transformada de Fourier (FTIR)}

As análises no modo transmissão foram realizadas em um espectrofotômetro FTIR da marca Thermo Nicolet, modelo Nexus 470. As amostras foram preparadas em formato de pastilhas através da diluição com brometo de potássio anidro, e por posterior prensagem da mistura. Os espectros foram coletados com 32 varreduras, e com uma resolução de $2,0 \mathrm{~cm}^{-1}$.

\section{Porosimetria de Adsorção-Dessorção de N2}

Esta análise foi realizada com 0 objetivo de determinar a área específica, o volume médio de poros, o diâmetro médio de poros e a constante de BET das amostras de diatomita in natura e diatomita-C1. As análises de porosimetria foram realizadas em um equipamento da marca Micromeritics, modelo Gemini VII 2390. As amostras foram pré-tratadas sob vácuo (10-1 bar) a uma temperatura de $80^{\circ} \mathrm{C}$ durante $48 \mathrm{~h}$. As análises foram realizadas com adsorção de nitrogênio. Com os resultados levantados foi feito uma isoterma de adsorção que demostra a relação entre a quantidade de gás que foi adsorvida ou dessorvida pelo sólido, em relação à pressão de trabalho e à pressão do gás a temperatura constante. (TEIXEIRA; COUTINHO; GOMES, 2001). As áreas específicas foram determinadas através do método de Brunauer-Emmett-Teller (BET) e os diâmetros médio de poros foram calculados pelo método de Barret-Joyner-Halenda (BJH).

\section{Microscopia eletrônica de varredura (SEM)}

As análises de SEM foram realizadas em um microscópio de bancada da marca HITACHI, modelo TM-1000. A voltagem de aceleração utilizada foi de $15 \mathrm{kV}$. Para a realização das análises, as amostras foram fixadas na forma de pó sobre uma fita de carbono em um porta amostras (stub) de alumínio e revestidas com ouro. Foram realizadas as imagens das amostras com magnificações de 250, 500, 1500 e 3000 vezes.

\section{Granulometria por difração a laser}

A granulometria por difração a laser foi realizada em um analisador da marca Malvern, modelo Mastersizer 2000, acoplado a um acessório Hydro 2000 UM (A). Para as análises, as amostras foram diluídas em isoparafina a uma concentração em torno de $0,10 \%(\mathrm{v} / \mathrm{v})$.

\section{Preparação doscompósitos poliméricos de PEAD/diatomita-C1}

O polietileno de alta densidade utilizado como matriz polimérica no presente trabalho possui o 1-buteno como comonômero, foi preparado industrialmente com o uso de um catalisador do tipo Ziegler-Natta, e contém aditivos antioxidantes e estabilizantes.

Nesse estudo, foram preparadas amostras de compósitos de PEAD-diatomita-C1, 
denominados de PE-D2 e PE-D5, contendo $2 \%$ e $5 \%(\mathrm{~m} / \mathrm{m})$ de diatomita-C1, respectivamente.

A pesagem da diatomita-C1 e do PEAD foi realizada em balança semi-analítica e a mistura dos componentes foi realizada de forma manual. Após mistura, as amostras foram extrudadas em uma extrusora da marca $A X$ Plásticos - Mini Extrusora AX DR 16:40, dupla rosca de aço SAE 8550.

Foram realizados testes iniciais com PEAD puro para determinar qual a melhor relação entre pressão de massa, rotação do dosador e da rosca para a extrusão das amostras. A pressão de massa utilizada foi de 15 bar, e as rotações do dosador e da rosca foram de $4 \mathrm{rpm}$ e $40 \mathrm{rpm}$, respectivamente. As temperaturas das zonas de aquecimento podem ser observadas na Tabela 1.

Tabela 1. Temperaturas das diferentes zonas de aquecimento da extrusora que foram utilizadas na preparação dos compósitos

\begin{tabular}{cc}
$\begin{array}{c}\text { Zona de } \\
\text { aquecimento da } \\
\text { extrusora }\end{array}$ & $\begin{array}{c}\text { Temperatur } \\
\mathbf{a}\left({ }^{\circ} \mathbf{C}\right)\end{array}$ \\
\hline Zona 1 & 90 \\
Zona 2 & 100 \\
Zona 3 & 130 \\
Zona 4 & 150 \\
Zona 5 & 170 \\
Zona 6 & 170 \\
Zona 7 & 175 \\
Zona 8 & 175 \\
Zona 9 & 175 \\
\hline
\end{tabular}

Foram extrudadas as amostras do compósito PEAD/diatomita contendo $2 \%$ e $5 \%$ de diatomita-C1. Para fins comparativos, foi também extrudada uma amostra de PEAD sem a adição de diatomita-C1, que para facilitar a discussão, foi denominada de PE.

\section{Caracterização dos compósitos poliméricos de PEAD/diatomita-C1}

Para avaliar a influência da adição da diatomita-C1 sobre as propriedades térmicas e mecânicas dos materiais compósitos com matriz de polietileno de alta densidade, foram realizadas algumas análises. As técnicas de caracterização e os ensaios de propriedades utilizados foram: microscopia eletrônica de varredura (MEV), análise termogravimétrica (TGA), calorimetria diferencial exploratória (DSC), análise dinâmicomecânica (DMTA), ensaio de resistência ao impacto Izod, ensaio de módulo de flexão e análise de resistência à tração.

\section{Microscopia eletrônica de varredura (SEM)}

As análises foram realizadas em um microscópio eletrônico de varredura JEOL, modelo JSM 6060 operando em $15 \mathrm{kV}$.

Um pellet de cada amostra foi cortado de forma a expor a superfície interna, sem alterar as características morfológicas do material. Posteriormente, cada amostra foi fixada em uma fita de carbono sobre um porta amostras (stub) e metalizada com ouro. Após estes procedimentos, foram realizadas as imagens das amostras com magnificação de 500 vezes.

\section{Análise termogravimétrica (TGA)}

As análises termogravimétricas foram realizadas em um analisador termogravimétrico TGA Q50 (TA Instruments). Cada amostra foi pesada em um cadinho de platina, e inserida no porta amostras do equipamento, 0 qual transportou a amostra até a célula de carga com posterior fechamento do forno. As amostras foram aquecidas da temperatura ambiente até $1000^{\circ} \mathrm{C}$ em uma taxa de $20^{\circ} \mathrm{C} / \mathrm{min}$ sob atmosfera inerte.

\section{Calorimetria diferencial exploratória (DSC)}

A análise foi realizada conforme ASTM D3418. As amostras foram pesadas e colocadas em um recipiente. Em seguida, as amostras foram colocadas na célula do calorímetro da marca TA Instruments, modelo Q100 e foram aquecidas até $200^{\circ} \mathrm{C}$, resfriadas até $-20^{\circ} \mathrm{C}$, e aquecidas novamente até $200^{\circ} \mathrm{C}$.

Com os dados obtidos na análise, foram plotadas as curvas de temperatura de fusão da segunda varredura (Tm2) e de temperatura de cristalização (Tc). Os resultados de cristalinidade foram calculados através da Equação 1, conforme a literatura apresentada por Hummel (1996), onde $\Delta \mathrm{H}_{f}$ é a variação de entalpia da amostra, $\Delta \mathrm{H}_{0}$ é a variaçao de entalpia de fusão do polietileno $100 \%$ cristalino.

$$
\mathrm{X}_{\mathrm{c}}(\%)=\frac{\Delta \mathrm{H}_{\mathrm{f}}}{\Delta \mathrm{H}_{0}} \times 100 \%
$$

A cristalinidade calculada através da fórmula acima foi corrigida de acordo com o 
percentual de diatomita adicionado na preparação do compósito. Essa correção é realizada através da divisão da $X_{c}$ pela fração mássica de PEAD no compósito.

\section{Análise dinâmico-mecânica (DMTA)}

Foram preparados corpos de prova através da moldagem por compressão em uma prensa pneumática da marca Carver, com espessura de $2 \mathrm{~mm}, 38 \mathrm{~mm}$ de comprimento e $13 \mathrm{~mm}$ de largura. As análises foram realizadas em um analisador DMA da marca TA Instruments, modelo Q800, em modo único cantilever a uma frequência de $1 \mathrm{~Hz}$ e na faixa de temperatura entre $-140^{\circ} \mathrm{C}$ a $100^{\circ} \mathrm{C}$. A taxa de aquecimento utilizada foi de $2{ }^{\circ} \mathrm{C} /$ minuto.

\section{Ensaio de resistência ao impacto Izod}

Para a análise, foram preparados 5 corpos de prova de cada amostra através da moldagem por compressão em uma prensa pneumática da marca Carver, com espessura de $3 \mathrm{~mm}, 13 \mathrm{~mm}$ de comprimento e $63,7 \mathrm{~mm}$ de largura. Os corpos de prova foram climatizados por $40 \mathrm{~h}$ a temperatura de $23 \pm 2^{\circ} \mathrm{C}$, antes da realização do ensaio. A análise de Impacto Izod foi realizada de acordo com a norma ASTM D256, no equipamento Resil Impactor da marca CEAST. O corpo de prova foi fixado verticalmente no suporte do equipamento e um pêndulo de $4 \mathrm{~J}$ foi liberado de uma altura pré-definida de forma a atingir o corpo de prova perpendicularmente.

\section{Ensaio de resistência à flexão}

Para a análise, foram preparados 5 corpos de prova através da moldagem por compressão em uma prensa pneumática da marca Carver, com espessura de $3 \mathrm{~mm}, 13 \mathrm{~mm}$ de comprimento e $126 \mathrm{~mm}$ de largura. Os corpos de prova foram climatizados por $40 \mathrm{~h}$ a temperatura de $23 \pm 2^{\circ} \mathrm{C}$.

O ensaio de módulo de flexão foi realizado de acordo com a norma ASTM D790, no dinamômetro da marca Instron, modelo 5581. Para realização do ensaio, o corpo de prova foi submetido a uma deformação com uma taxa prédefinida de $13 \mathrm{~mm} /$ minuto. Durante a flexão, o corpo de prova foi submetido a esforços de tração e compressão. A resposta a cada deformação foi indicada por uma célula de carga, e o resultado foi calculado conforme descrito na norma ASTM D790 (2015).

\section{Ensaio de resistência à tração}

Para a análise, foram preparados 5 corpos de prova através da moldagem por compressão em uma prensa pneumática da marca Carver, com espessura de $3 \mathrm{~mm}, 13 \mathrm{~mm}$ de comprimento e $126 \mathrm{~mm}$ de largura. Os corpos de prova foram climatizados por $40 \mathrm{~h}$ a temperatura de $23 \pm 2^{\circ} \mathrm{C}$.

$O$ ensaio foi realizado segundo norma ASTM D638, em uma máquina de ensaio de tração Instron 5581, onde os corpos de prova foram submetidos a uma força continuamente crescente até se observar a ruptura.

\section{RESULTADOS E DISCUSSÃO}

Conforme a proposta da metodologia, os resultados e discussão serão divididos em duas partes: caracterização da diatomita e propriedades dos compósitos PEAD/diatomita-C1.

\section{Caracterização da diatomita}

As diatomitas podem ser classificadas como sílicas naturais biogênicas. As diatomitas possuem característica hidrofílica devido à presença de grupos silanóis na superfície, que tornam esse agente de reforço incompatível com a matriz de PEAD, que é essencialmente hidrofóbica. Com o objetivo de viabilizar a compatibilização entre a diatomita e a matriz de PEAD, foi realizada a organofuncionalização da diatomita com 0 reagente metiltrietoxisilano. De maneira a facilitar a discussão dos resultados, a diatomita organofuncionalizada será denominada de diatomita-C1. Considerando que não foi fornecida pelo fabricante informações sobre as características da diatomita, a mesma foi caracterizada através de um conjunto de técnicas complementares de análise, de modo a se obter informações sobre a natureza das espécies de superfície, propriedades texturais e morfológicas do material. As mesmas caracterizações foram realizadas para a diatomita organofuncionalizada.

\section{Natureza das espécies de superfície}

A caracterização estrutural da diatomita in natura e organofuncionalizada foi realizada através da técnica de Espectroscopia no Infravermelho com Transformada de Fourier (FTIR), no modo de transmissão. Os espectros de FTIR para esses materiais são apresentados 
na Figura 1.

A interpretação dos espectros foi realizada com base nas literaturas de Lin-Vien et al. (1991) e Ramos et al. (1998).O espectro da diatomita in natura apresenta bandas centradas em 796 e $1100 \mathrm{~cm}^{-1}$, que podem ser atribuídas respectivamente aos estiramentos simétricos $v_{s}(\mathrm{Si}-\mathrm{O})$ e assimétricos $\mathrm{V}_{\mathrm{as}}(\mathrm{Si}-\mathrm{O})$ dos grupos siloxano (Si-O-Si). As mesmas bandas são observadas no espectro da diatomita organofuncionalizada com metiltrietoxisilano. A banda larga centrada em $3441 \mathrm{~cm}^{-1}$, observada no espectro da diatomita in natura, é referente ao estiramento $v(\mathrm{O}-\mathrm{H})$ dos grupos silanóis ( $(\mathrm{Si}-\mathrm{OH})$ vicinais e geminais e de água adsorvida. A banda em $3740 \mathrm{~cm}^{-1}$ pode ser atribuída ao estiramento $\checkmark(\mathrm{O}-\mathrm{H})$ dos grupos silanóis isolados. $\mathrm{O}$ espectro da diatomita in natura apresenta também bandas centradas em 2961, 2922 e $2851 \mathrm{~cm}^{-1}$, atribuídas ao estiramento assimétrico $\mathrm{V}_{\mathrm{as}}(\mathrm{C}-\mathrm{H})$ de grupos metila $\left(\mathrm{CH}_{3}\right)$, estiramento assimétrico $v_{\text {as }}(\mathrm{C}-\mathrm{H})$ e simétrico $v_{s}(\mathrm{C}-\mathrm{H})$ de grupos etila $\left(\mathrm{CH}_{2}\right)$, respectivamente. A presença dessas bandas evidencia a existência de matéria orgânica no material in natura.

Após a organofuncionalização, ocorre a intensificação e o deslocamento das bandas atribuídas aos estiramentos $\mathrm{C}-\mathrm{H}$. Além disso, ocorre o aparecimento de bandas em 851 e 1261 $\mathrm{cm}^{-1}$ referentes às vibrações $\mathrm{Si}-\mathrm{C}$ e $\mathrm{C}-\mathrm{H}$ (de grupos $\left.-\mathrm{OCH}_{2}-\right)$. Essa alteração no espectro de infravermelho ocorre devido à presença de grupos metila e etóxido $\left(\mathrm{O}-\mathrm{CH}_{2}-\mathrm{CH}_{3}\right)$ do metiltrietoxisilano na superfície da diatomita. Cabe salientar que a reação de organofuncionalização ocorre pela substituição do hidrogênio dos grupos silanóis da diatomita pelo silício das moléculas do reagente metiltrietoxisilano com a liberação de etanol, que é removido no processo de secagem. (VANSANT; VOORT; VRANCKEN, 1995).

\section{Hidrofobicidade da superfície}

De maneira a investigar se a organofuncionalização da diatomita resulta em efetiva redução da polaridade da superfície (aumento da hidrofobicidade), foi realizado um ensaio de dispersão do pó de diatomita em água, cujo resultado é apresentado na Figura 2.

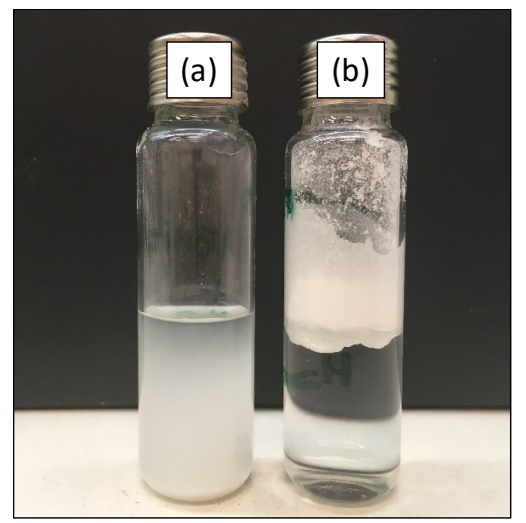

Figura 2. Ensaio de hidrofobicidade: (a) diatomita in natura com água e (b)diatomita-C1 com água

Através da Figura 2, é possível observar que a diatomita in natura é dispersada em água, evidenciando seu comportamento hidrofílico. Por outro lado, a diatomita-C1 não é dispersada em água. Esse resultado mostra que a organofuncionalização da diatomita com metiltrimetoxisilano aumenta 0 caráter hidrofóbico do material, reduzindo, portanto, a polaridade da superfície. Esse comportamento é devido à presença dos grupos $\mathrm{CH}_{3}$ (apolares) e ao menor teor de grupos silanóis (polares) na superfície da diatomita-C1, como mostrado pelos resultados de FTIR.

\section{Propriedades texturais}

De modo a investigar as propriedades texturais (área específica, diâmetro e volume médio de poros, constante de BET) da diatomita in natura e diatomita- $\mathrm{C} 1$, esses materiais foram caracterizados pela técnica de porosimetria de adsorção-dessorção de $\mathrm{N}_{2}$, cuja isoterma típica é apresentada na Figura 3.

A isoterma de adsorção-dessorção de $\mathrm{N}_{2}$ da Figura 3 é do tipo II (Classificação IUPAC), característica de materiais não porosos ou macroporosos, como é o caso da diatomita. Resultado similar foi observado para a diatomita modificada com grupos metilsilano (C1).

Os resultados de área específica $\left(S_{B E T}\right)$, volume médio de poros $\left(V_{p}\right)$, diâmetro médio de poros $\left(D_{p}\right)$ e constante de BET $(C)$ para a diatomita in natura e diatomita-C1 são apresentados na Tabela 2. 
Tabela 2. Propriedades texturais da diatomita in natura e da diatomita-C1, obtidas por porosimetria de adsorção-dessorção de $\mathrm{N}_{2}$

\begin{tabular}{lcccc}
\hline Sistema & $\begin{array}{c}\mathbf{S}_{\mathrm{BET}} \\
\left(\mathbf{m}^{\mathbf{2}} \mathbf{g}^{-1}\right)\end{array}$ & $\begin{array}{c}\mathbf{V p} \\
\left(\mathbf{c m}^{\mathbf{3}} / \mathbf{g}\right. \\
)\end{array}$ & $\begin{array}{c}\mathbf{D p} \\
(\AA)\end{array}$ & $\mathbf{C}$ \\
\hline Diatomit & 1,36 & 0,0017 & 122 & 9 \\
a in & & & & 9 \\
natura & & & & \\
$\quad$ Diatomit & 0,48 & 0,0004 & 97 & 2 \\
$\quad$ a-C1 & & 4 & & 5 \\
\hline
\end{tabular}

De acordo com a Tabela 2, a diatomita in natura apresentou área específica de BET de $1,36 \mathrm{~m}^{2} \mathrm{~g}^{-1}$. Esse valor de $\mathrm{S}_{\mathrm{BET}}$ é da mesma ordem de grandeza daquele observado por Tsai et al. (2006) que é de $3,81 \mathrm{~m}^{2} \mathrm{~g}^{-1}$. Entretanto, a área específica BET da diatomita é consideravelmente inferior àquela observada para sílicas sintéticas comerciais que é de 100$900 \mathrm{~m} / \mathrm{g}$. (ZHURAVLEV, 2000). Após a organofuncionalização com metiltrimetoxisilano, observa-se uma redução da $S_{B E T}$. Esse comportamento foi descrito por Ambrozewicz et al. (2013), e pode ser atribuído ao recobrimento parcial dos sítios de adsorção na superfície da diatomita pelas moléculas do organosilano. Pode-se observar também uma redução no volume e diâmetro médio de poros, evidenciando um preenchimento dos poros pelas moléculas do organosilano.

A constante $\mathrm{C}$ de BET apresentou um decréscimo significativo após a modificação da diatomita com grupos metilsilano, indicando que a interação entre o sólido e o $\mathrm{N}_{2}$ diminuiu com 0 recobrimento parcial da superfície pelas moléculas do organosilano. De acordo com Alloul et al. (2016), a constante pode ser utilizada como uma medida da polaridade de superfícies e quanto mais elevado for o seu valor, maior será a polaridade do material. Portanto, o decréscimo do valor de $\mathrm{C}$ com a modificação da diatomita pode ser atribuído à redução da polaridade da superfície do material, como já discutido no ensaio de hidrofobicidade.

\section{Distribuição de tamanho de partículas}

As curvas de distribuição de tamanho de partículas da diatomita in natura e diatomita$\mathrm{C} 1$, obtidas pela na técnica de granulometria de difração a laser são apresentadas na Figura 4.

De acordo com a Figura 4, as amostras apresentam partículas com diâmetro entre 1 e $100 \mu \mathrm{m}$, aproximadamente. O diâmetro médio de partículas (d50) da diatomita in natura foi de $31,2 \mu \mathrm{m}$. Já para a diatomita-C1 0 diâmetro médio de partículas foi de 20,5 $\mu \mathrm{m}$. Cabe salientar que o diâmetro médio de partícula da diatomita-C1, material escolhido para a investigação do presente trabalho, é relativamente maior, se comparado a outros trabalhos que utilizaram sílica como carga em matriz polimérica de PEAD. Ramos (2017) utilizou uma sílica como diâmetro médio de partícula de 5,65 $\mu \mathrm{m}$. Dorigato, D'Amato e Pegoretti (2012) usaram nanoparticulas de sílicas. Gao, Liu e Wei (2011) utilizaram sílicas com partículas da ordem de $61 \mu \mathrm{m}$.

Além disso, o diâmetro médio de partículas da diatomita in natura foi superior ao da organofuncionalizada, indicando que a diatomita tende a aglomeração, que é reduzida pela modificação da superfície com grupos metilsilano. Resultado similar foi observado por Brambilla et al. (2007) em um estudo envolvendo a modificação de sílicas pirogênicas com grupos octadecilsilano. Entretanto, não se pode descartar que o processo de agitação durante a etapa de modificação da diatomita tenha resultado em quebra de algumas partículas.

\section{Morfologia das partículas}

Com o objetivo de avaliar a morfologia das partículas da diatomita in natura e diatomita$\mathrm{C} 1$, esses materiais foram caracterizados pela técnica de microscopia eletrônica de varredura (SEM), cujas micrografias são apresentadas na Figura 5.

Através das micrografias da Figura 5, pode-se observar que uma grande parte das partículas de diatomita apresenta forma irregular. Pode-se observar também algumas partículas com morfologia característica de diatomita do tipo circular. Além disso, não há modificação da morfologia das partículas de diatomita com a organofuncionalização, indicando que não ocorreu a formação de agregados, oriundos da hidrólise e condensação do metiltrimetoxisilano, mas sim recobrimento das partículas pelas moléculas desse organosilano. Ademais, foi possível observar também alguns macroporos na superfície da partícula de morfologia circular, característica que justifica o fato das diatomitas serem comumente utilizadas em processos de filtração.

\section{Avaliação das propriedades morfológicas, térmicas e mecânicas dos compósitosde PEAD/diatomita-C1}


No presente trabalho, compósitos de PEAD/diatomita-C1, contendo 2 e $5 \%(\mathrm{~m} / \mathrm{m})$ de diatomita-C1, foram preparados através do método de extrusão, caracterizados e avaliados por uma série de técnicas e ensaios de propriedades, de maneira a avaliar suas propriedades morfológicas, térmicas e mecânicas.

De maneira a facilitar a discussão dos resultados, as amostras de compósitos, contendo 2 e $5 \%$ de diatomita-C1, foram denominadas de PE-D2 e PE-D5, respectivamente. O polietileno de alta densidade (PEAD) puro foi denominado de PE.

As análises e interpretações referentes a caracterização desses compósitos serão apresentadas a seguir.

\section{Caracterização morfológica}

Com o objetivo de avaliar a morfologia dos compósitos PEAD/diatomita-C1 e avaliar a distribuição da diatomita nesses materiais, foram realizadas análises de microscopia eletrônica de varredura. A Figura 6 apresenta as micrografias de microscopia eletrônica de varredura (SEM) do PEAD puro e dos materiais compósitos.

As micrografias de SEM dos compósitos de $\mathrm{PEAD/diatomita-C1}$ revelam a presença de dois domínios distintos, que estão indicados no detalhe na Figura 6. Um dos domínios é predominantemente formado pela matriz de PEAD e o outro é constituído de aglomerados de partículas de diatomita-C1. A existência desses dois domínios sugere uma distribuição não uniforme da diatomita-C1 nos materiais compósitos, que pode ser resultante de uma fraca interação entre as partículas de tamanho micrométrico de diatomita-C1 e a matriz de PEAD.

\section{Propriedades térmicas}

As curvas termogravimétricas (TGA) e de termogravimetria derivada (DTG) do PEAD puro e dos compósitos de PEAD/diatomita-C1 são apresentadas na Figura 7 e Figura 8 respectivamente, na qual podem ser obtidos resultados referentes à estabilidade térmica dos materiais.

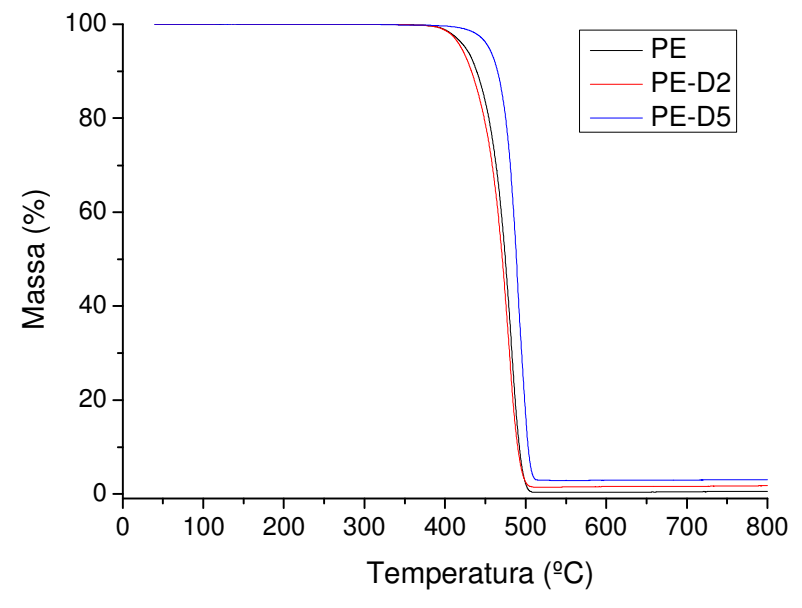

Figura 7. Curvas de TGA do PEAD e dos compósitos de PEAD/diatomita-C1

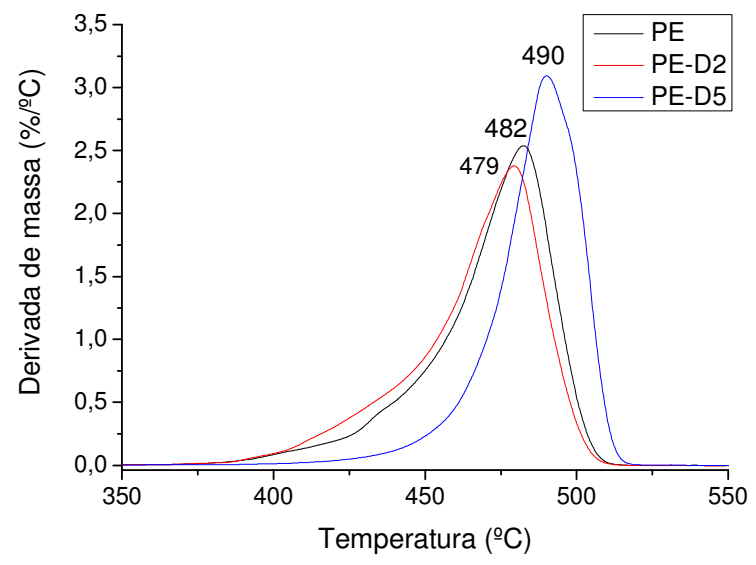

Figura 8. Curvas de DTG do PEAD e dos compósitos de PEAD/diatomita-C1

Através da análise da Figura 7 , podese observar apenas um estágio de perda de massa para todos os materiais. Pode-se observar também que a diatomita-C1 influencia a estabilidade térmica da matriz de PEAD. Esse efeito é mais destacado para o compósito PE-D5, com maior teor de diatomita-C1, pois sua curva de TGA apresenta-se deslocada para temperaturas maiores em comparação ao PEAD puro. Em relação aos resíduos na temperatura de $800{ }^{\circ} \mathrm{C}$, o PEAD puro apresentou um resíduo de $0,82 \%$. Como esperado, o aumento da percentagem mássica de diatomita no compósito resultou em um maior teor de resíduo na temperatura de $800{ }^{\circ} \mathrm{C}$. Os compósitos PE-D2 e PE-D5 apresentaram resíduos de 1,9 e 3,1\%, respectivamente.

De acordo com a Figura 8, o PEAD puro apresentou uma temperatura máxima de perda de $482{ }^{\circ} \mathrm{C}$, que está de acordo com o resultado reportado por Chrissafis et al. (2009). Além disso, a curva de DTG da Figura 8 mostra que a adição de 5,0 \% de diatomita-C1 ao PEAD 
resulta em um aumento de $8,0^{\circ} \mathrm{C}$ na temperatura máxima de perda.

De acordo com o DNPM (2017), a diatomita é um bom isolante térmico. Dorigato, D'Amato e Pegoretti (2012,) em estudos utilizando sílicas comerciais em matriz de polietileno, sugerem que 0 aumento da estabilidade térmica está associado ao fato das partículas de sílica atuarem como isolantes térmicos e limitarem a difusão de oxigênio na matriz polimérica, retardando o processo termooxidativo.

De maneira a investigar o efeito da presença da diatomita-C1 na temperatura de fusão $\left(T_{m}\right)$, temperatura de cristalização $\left(T_{c}\right)$ e cristalinidade $\left(X_{C}\right)$ do PEAD, os materiais foram caracterizados pela técnica de calorimetria diferencial exploratória (DSC). As curvas de DSC para o PEAD e compósitos de PEAD/diatomitaC1 são apresentadas nas Figuras 9 e 10.

A Tabela 3 apresenta os resultados de $T_{m}, T_{c}$ e $X_{c}$ (corrigida pelo teor de diatomita) dos materiais, obtidos a partir das curvas de DSC.

Tabela 3.Resultados de calorimetria diferencial exploratória (DSC) para o PEAD e compósitos de PEAD-diatomita-C1

\begin{tabular}{cccc}
\hline $\begin{array}{c}\text { Sistem } \\
\mathbf{a}\end{array}$ & $\begin{array}{c}\mathbf{T}_{\mathbf{m}} \\
\left({ }^{\circ} \mathbf{C}\right)\end{array}$ & $\mathbf{T}_{\mathbf{c}}\left({ }^{\circ} \mathbf{C}\right)$ & $\mathbf{X}_{\mathbf{c}}(\%)$ \\
\hline PE & 133 & 119 & 72 \\
PE-D2 & 132 & 120 & 77 \\
PE-D5 & 133 & 119 & 78 \\
\hline
\end{tabular}

De acordo com a Tabela 3, os resultados de temperatura de fusão e cristalização para a amostra PE foram de aproximadamente de $133{ }^{\circ} \mathrm{C}$ e $120{ }^{\circ} \mathrm{C}$, respectivamente. Esses valores são típicos de polietileno de alta densidade. Coutinho, Maria e Mello (2003) mencionam em sua revisão que a $\mathrm{Tm}$ para o PEAD do variar entre $128^{\circ} \mathrm{C}$ e $135^{\circ} \mathrm{C}$, dependendo da sua densidade. Zhang, Rong e Zhang (2003) observaram uma temperatura de cristalização para o PEAD em torno de $119^{\circ} \mathrm{C}$.

$A$ adição de diatomita ao $P E A D$ não influenciou de forma significativa a Tm e a Tc dos materiais. Entretanto, pode-se observar uma ligeira variação na cristalinidade. Para o PEAD, o valor de cristalinidade foi $72 \%$, que está de acordo com aquele reportado por Peacock (2000).
Os compósitos de PEAD/diatomitaC1 apresentaram cristalinidade de 77-78 \%. Este acréscimo de cristalinidade, pode ser atribuído, segundo Lima (2007), ao aumento da fração cristalina e diminuição da fração amorfa do PEAD, sugerindo que a diatomita atua como um agente nucleante.

\section{Propriedades dinâmico-mecânicas}

A análisede DMTA dá informações a respeito do comportamento visco-elástico do material compósito, e pode obter informações de dois componentes: módulo de armazenamento (deformação elástica) e o módulo de perda (deformação viscosa). (WUNDERLICH, 1997). No presente trabalho, serão discutidos os resultados do módulo de armazenamento (G') dos materiais, conforme apresentado na Figura 11 e Tabela 4.

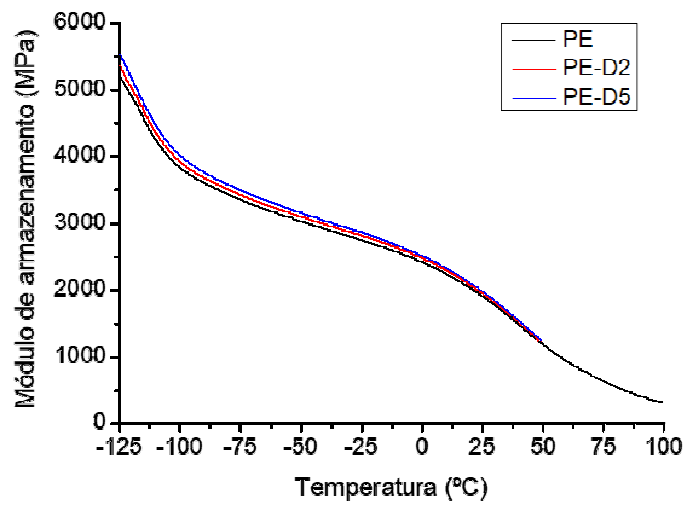

Figura 11. Curva do módulo de armazenamento (G') em função da temperatura para o PEAD e compósitos de PEAD/diatomita-C1

Tabela 4. Resultados de G' $\left(23^{\circ} \mathrm{C}\right)$ para o PEAD e compósitos dePEAD/diatomita-C1, obtidos a partir da curva de DMTA

\begin{tabular}{cc}
\hline Sistema & G' (MPa) \\
\hline PE & 1956 \\
PEAD-D2 & 1997 \\
PEAD-D5 & 2028
\end{tabular}

Pode-se observar na Figura 11 um pequeno deslocamento das curvas para maiores valores de G' com o aumento do teor de diatomita nos materiais. De acordo com a Tabela 4, o compósito com 5,0\% de diatomita (PEADD5) apresentou um módulo de armazenamento $3,6 \%$ superior aquele observado para o PEAD puro. Portanto, os compósitos de PEADdiatomita-C1 são um pouco mais rígidos que 0 PEAD puro. Esse aumento de rigidez sugere a 
formação de uma discreta rede de reforço entre a diatomita e o PEAD. Um aumento mais significativo do módulo de armazenamento pode ter sido limitado pela distribuição não uniforme da diatomita-C1 nos materiais compósitos (observada nas imagens de SEM), formando aglomerados que dificultam a interação cargamatriz.

Entretanto, não se pode negligenciar o efeito da cristalinidade dos materiais no módulo de armazenamento. De acordo com os resultados de DSC e DMTA, o aumento da cristalinidade dos materiais resultou em um aumento do módulo de armazenamento. Resultado similar já foi observado por Dorigato, D'amato e Pegoretti (2012), em um estudo envolvendo a obtenção de compósitos de PEAD/sílica, e foi atribuído ao fato dos cristais de polietileno atuarem como pontos que restringem o movimento molecular, levando a um aumento de rigidez.

\section{Ensaio de resistência ao impacto Izod}

Com o objetivo de investigar o efeito da presença de diatomita-C1 no PEAD sobre a resistência ao impacto dos compósitos, foram realizados ensaios de impacto Izod, cujos resultados são apresentados na Figura 12.

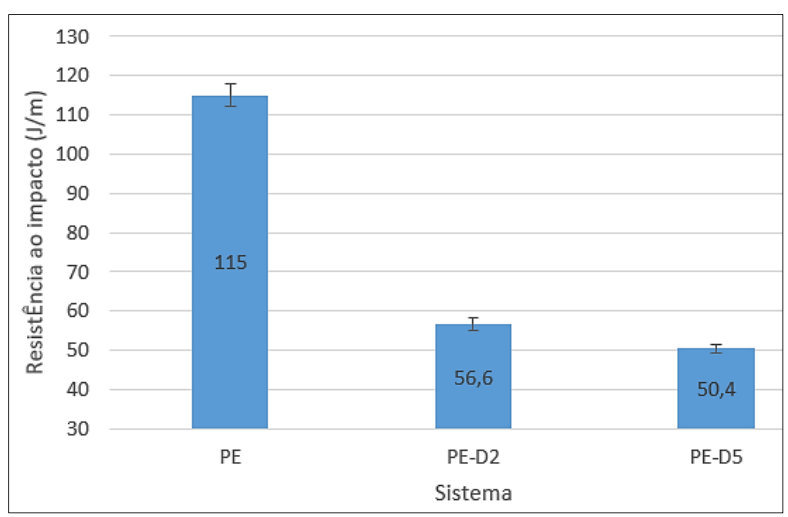

Figura 12. Resultados de resistência ao impacto Izod para o polietileno de alta densidade (PEAD) e compósitos de PEAD/diatomita-C1

De acordo com a Figura 12, o valor de resistência ao impacto para o PEAD puro foi de $115 \mathrm{~J} / \mathrm{m}$. Segundo Peacock (2000), os resultados de resistência ao impacto Izod esperados para uma amostra de PEAD, apresentam uma ampla faixa de aceitação, podendo estar entre 20 e $215 \mathrm{~J} / \mathrm{m}$. Os compósitos do presente trabalho encontram-se nessa faixa. Pode-se observar que a adição de diatomita-C1 ao PEAD resulta em uma acentuada redução da resistência ao impacto. Os compósitos de $\mathrm{PEAD/diatomita-C1}$ apresentaram uma resistência ao impacto aproximadamente 50 $\%$ inferior àquela observada para o PEAD puro. Dangtungee, Rattanapan e Siengchin (2015) obtiveram resultado semelhante onde foi observado uma queda da resistência ao impacto com o aumento do teor de carga (carbeto de silício) em compósitos de matriz de PEAD. Eles atribuíram 0 resultado à existência de microespaços entre a carga e a matriz polimérica, resultante da fraca interação interfacial SiCPEAD. De acordo com os pesquisadores, esses microespaços resultam em microfissuras quando o impacto ocorre, propagando mais facilmente a trinca, e diminuindo a resistência ao impacto dos compósitos.

No presente trabalho, o decréscimo da resistência ao impacto com a adição de diatomita-C1 tem explicação semelhante. As partículas de diatomita-C1, devido ao tamanho micrométrico, interagem fracamente com a matriz de PEAD, resultando em aglomerados maiores de partículas heterogeneamente distribuídos no compósito que facilitam as microfissuras, reduzindo a capacidade do material de absorver a energia de impacto.

\section{Ensaio de flexão}

A fim de medir a capacidade dos materiais de resistirem a uma deformação sob carga, foram realizados ensaios de flexão. Os resultados desses ensaios para PEAD e para os compósitos poliméricos de PED/diatomita-C1 são apresentados na Figura 13.

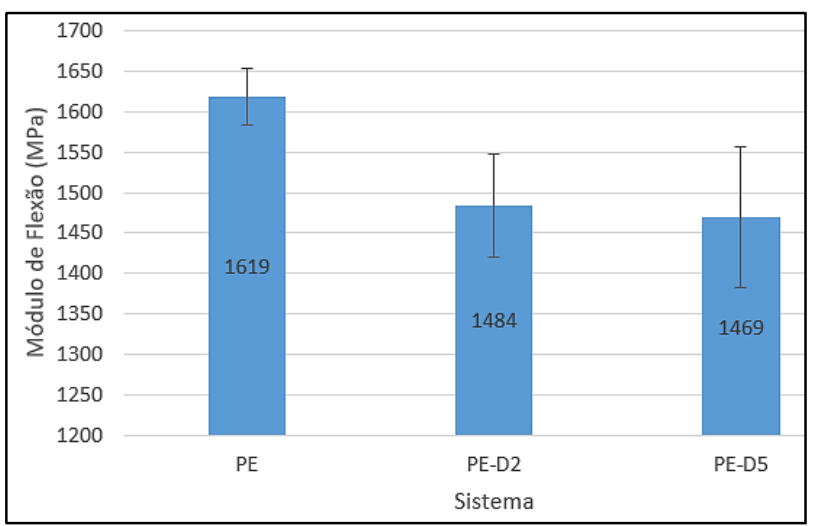

Figura 13. Resultados de módulo de flexão para o PEAD e compósitos de PEAD-diatomita-C1

De acordo com a Figura 13, o valor do módulo de flexão para o PEAD foi de 1619 35 $\mathrm{MPa}$, que está de acordo com o reportado por Peacock (2000). A adição de diatomita-C1 ao PEAD resultou em uma ligeira redução do módulo de flexão. A adição de $2,0 \%$ de 
diatomita-C1, por exemplo, resultou em um módulo de flexão de $1484 \pm 64 \mathrm{MPa}$. Esse valor corresponde a uma redução de 8,3 \%, em comparação ao módulo de flexão do PEAD puro. Contudo, esse resultado é superior aquele reportado por Dorigato D'amato e Pegoretti (2012), que observaram um módulo de flexão de $1190 \pm 20 \mathrm{MPa}$ para um compósito de PEAD com $2,0 \%$ de sílica. O aumento do teor de diatomita-C1 para 5,0 \% não resulta em redução significativa do módulo de flexão em relação ao compósito PE-D2, com 2,0 \% de diatomita-C1.

Segundo Jeziórska et al. (2014), as propriedades de flexão estão associadas às interações interfaciais entre a carga e a matriz polimérica, e o aumento do módulo de flexão é observado quando há forte interação entre esses dois componentes.

Firmino et al. (2017) investigou a adição de pó de concha de tamanho micrométrico e nanométrico em PEAD e verificou que a adição da carga com tamanho micrométrico, em teores maiores que $2,0 \%$, resulta em um decréscimo do módulo de flexão. Comportamento oposto foi observado para as partículas nanométricas de pó de concha. Esse resultado foi atribuído à menor área superficial das partículas micrométricas, que diminuí a molhabilidade das mesmas pela matriz polimérica.

Como no presente trabalho foi verificada uma pequena redução no módulo de flexão com adição de diatomita-C1, pode-se inferir que a interação entre 0 as partículas de diatomita-C1 e a matriz de PEAD é uma interação fraca ou, pelo menos, insuficiente para garantir um reforço em termos de resistência à flexão. Além disso, visto que a modificação da diatomita com grupos $\mathrm{CH}_{3}$ conferiu um caráter apolar à essa carga, e que a área específica (S $S_{B E T}$ ) da diatomita modificada apresentou um valor extremamente baixo em relação àquelas observadas na literatura para sílicas sintéticas, a fraca interação matriz-carga é possivelmente uma consequência da baixa molhabilidade das partículas micrométricas de diatomita-C1 pelo PEAD e não da polaridade da superfície das mesmas.

\section{Ensaio de resistência à tração}

De maneira a investigar o efeito da presença de diatomita-C1 em matriz de polietileno de alta de alta densidade (PEAD) sobre a resistência mecânica à tração dos materiais resultantes, o PEAD e os compósitos foram submetidos ao ensaio de resistência à tração, cujos resultados são apresentados na Figura 14.

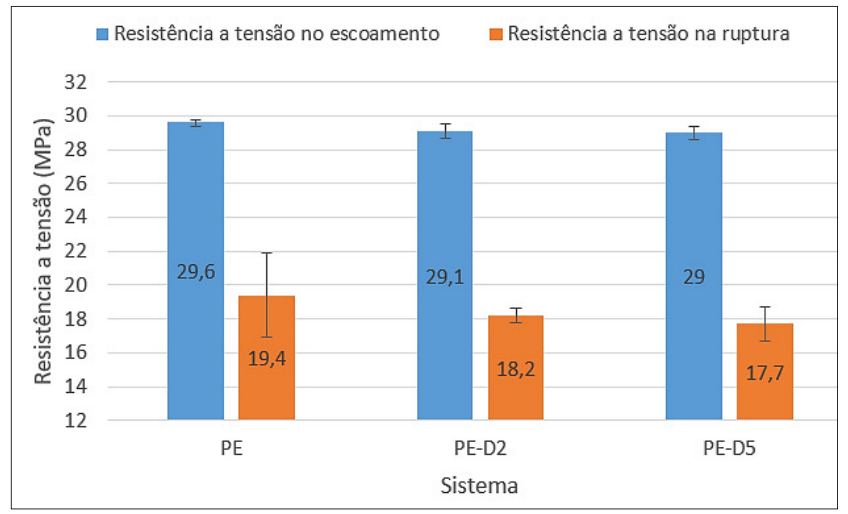

Figura 14.Resultados de resistência à tração para o PEAD e compósitos de PEAD-diatomitaC1

De acordo com a Figura 14, a adição de diatomita-C1 ao PEAD não influenciou as propriedades mecânicas de tensão no escoamento e tensão na ruptura. De acordo com Peacock (2000), os resultados de tensão no escoamento para o PEAD devem estar entre 17,92 e $31 \mathrm{MPa}$ e os resultados de tensão na ruptura devem estar entre 22,1 e $31 \mathrm{MPa}$.

Dorigato, D'Amato e Pegoretti (2012) estudaram a resistência à tração de compósitos de PEAD contendo $2,0 \%$ de sílica manométrica organofuncionalizada e observaram aumento da tensão no escoamento e na ruptura em relação ao PEAD puro. Esse resultado foi atribuído à forte interação de interface entre as nanopartículas e a matriz polimérica. Entretanto, em termos numéricos os resultados foram próximos ao do presente trabalho. Para fins comparativos, a tensão no escoamento observada nesse trabalho da literatura foi de 29,6 $\pm 0,5 \mathrm{MPa}$.

Os resultados de resistência à tração obtidos no presente trabalho corroboram com a hipótese discutida anteriormente de que a interação entre as partículas micrométricas de diatomita-C1 e a matriz de PEAD foi insuficiente para criar uma rede de reforço adequada para o aumento dos valores das propriedades mecânicas dos materiais compósitos.

\section{CONCLUSÕES}

O presente trabalho teve como objetivo geral avaliar as potencialidades e limitações da utilização da diatomita organofuncionalizada com grupos metilsilano como agente de reforço em compósitos, utilizando o PEAD como matriz 
polimérica. As potencialidades encontradas foram o aumento da estabilidade térmica para o compósito preparado com maior teor de diatomita-C1 e a manutenção das propriedades de resistência à tração do PEAD. Esses resultados sugerem a possibilidade de utilização desse material em outras aplicações que explorem as características térmicas do mesmo.

Como limitações dos compósitos obtidos, pode-se mencionar a queda das propriedades de impacto Izod e de resistência à flexão em relação ao PEAD puro. Uma hipótese para a explicação desses resultados é a fraca interação entre o PEAD e a diatomita- $\mathrm{C} 1$, mais em virtude do tamanho micrométrico das partículas da carga do que pela polaridade de superfície da mesma.

Os resultados obtidos demonstraram que a organofuncionalização da diatomita com grupos metilsilano alterou suas propriedades superficiais e texturais. A organofuncionalização foi comprovada através da técnica de FTIR, na qual foi constatado o aparecimento de bandas características dos grupos funcionais metila após a modificação superficial. Em relação às propriedades texturais e de superfície, a modificação da diatomita proporcionou uma redução da área específica ( $\mathrm{S}_{\mathrm{BET}}$ ) e da constante de BET, medida da polaridade da superfície.

Para trabalhos futuros, sugere-se 0 estudo da adição de outras porcentagens de diatomita ao PEAD, para uma melhor avaliação da influência da quantidade da diatomita adicionada sobre as propriedades finais do compósito. Além disso, poderia ser realizado uma moagem e a separação das frações com diferentes tamanhos de partícula, para avaliar se a redução do diâmetro de partícula da diatomita resultará em melhorias das propriedades mecânicas dos compósitos. Em relação a modificação superficial da diatomita, sugere-se o estudo do efeito da utilização de diferentes teores de metilsilanonas propriedades dos compósitos resultantes.

\section{REFERÊNCIAS}

1. ALLOUL, H.; ROQUES-CARMES, T.; TOUFAILY, J.; KASSIR, M.; PELLETIER, M.; RAZAFITIANAMAHARAVO, A.; HAMIEH, T.; VILLIÉRAS, F. Towards a better description of organosilane grafting onto silica particles using volumetric techniques based on molecular probing. Adsorption, v. 22, n. 7, p. 923-937, 2016.

2. AMBROZEWICZ, D.; CIESIELCZYK, F.;
NOWACKA, M.; KARASIEWICZ, J.; PIASECKI, A.; MACIEJEWSKI, $H$. JESIONOWSKI, T. Fluoroalkylsilane versus alkylsilane as hydrophobic agents for silica and silicates. Journal of Nanomaterials, v. 2013, p.18, 2013.

3. ASSOCIAÇÃO BRASILEIRA DA INDÚSTRIA DO PLÁSTICO (ABIPLAST). Perfil 2015: Indústria Brasileira de Transformados Plásticos. São Paulo, 2015.

4. BERGNA, H. E.; ROBERTS, W. O. Colloidal silica: fundamentals and applications. 1. ed. CRC Press, 2006.

5. BRAMBILLA, R.; PIRES, G. P.; DOS SANTOS, J. H.Z., MIRANDA, M. L.; CHORNIK, B. Octadecylsilane-modified silicas prepared by grafting and sol-gel methods. Journal of electron spectroscopy and related phenomena. $v$. 156, p. 413-420, 2007.

6. BREESE, R. O. Y (1994). Diatomite. In: Industrial Minerals and Rocks, Ed. SMME, 6a edition, Senior Editor: CARR, D. D., p.397-412.

7. COUTINHO, F. M. B.; MARIA, L. C. de Santa; MELLO, I. L. Polietileno: Principais Tipos, Propriedades e Aplicações. Polímeros: Ciência e Tecnologia, São Paulo, v. 13, n. 1, p. 1-13, 2003.

8. CHRISSAFIS, K.; PARASKEVOPOULOS, K.M.; TSIAOUSSIS, I.; BIKIARIS, D. Comparative study of the effect of different nanoparticles on the mechanical properties, permeability, and thermal degradation mechanism of HDPE. Journal of Applied Polymer Science, v. 114, n. 3, p. 1606-1618, 2009.

9. DANGTUNGEE, R.; RATTANAPAN, A.; SIENGCHIN, S. The Effect of Surface Modifiers on the Mechanical and Morphological Properties of Waste Silicon Carbide Filled High-Density Polyethylene. Journal of Materials and Metallurgical Engineering, v. 1, n. 1, 2015.

10. Departamento nacional de produção mineral (DNPM). Disponível em: <http://www.dnpm.gov.br/>. Acesso em: 12 set. 2017.

11. DORIGATO, A.; D'AMATO, M.; PEGORETTI, A. Thermo-mechanical 
properties of high density polyethylenefumed silica nanocomposites: effect of filler surface area and treatment. Journal of Polymer Research, v. 19, n. 6, p. 1-11, 2012.

12. FIRMINO, H. C. T.; CHAGAS, T. F.; MELO, P. M. A.; SILVA, L. B. Caracterização de compósitos particulados de polietileno de alta densidade/pó de concha de molusco. Matéria (Rio J.), Rio de Janeiro, v. 22, n. 2, 2017 .

13. GAO, J. L.; LIU, Y. H.; WEI, S. D. Preparation and properties of Highdensity polyethylene/silica composites. Advanced Materials Research, v. 279, p. 115-119, 2011.

14. HUMMEL, D. O. Atlas of Polymer and Plastics Analysis. 3 ed., Vol.1, 1996.

15. JEZIÓRSKA, R.; ZIELECKA, M.; GUTAROWSKA, B.; GAKOWSKA, Z. High-Density Polyethylene Composites Filled with Nanosilica Containing Immobilized Nanosilver or Nanocopper: Thermal, Mechanical, and Bactericidal Properties and Morphology and Interphase Characterization. Journal of Polymer Science, v. 2014, 2014.

16. LIMA, A. B. T. Aplicações de cargas minerais em polímeros. Dissertação de mestrado em engenharia. Escola politécnica da Universidade de São Paulo, 2007.

17. LIN-VIEN, D.; COLTHUP, N. B.; FATELEY, W. G.; GRASSELLI, J. G. The Handbook of Infrared and Raman Characteristic Frequencies of Organic Molecules. 1 Ed. Nova York: Academic Press, 1991.

18. LUZ, A. B.; LINS, F. A. F. Rochas \& minerais industriais. Rio de Janeiro: CETEM/MCT, p. 399-411, 2005.

19. PEACOCK, A. J. Handbook of polyethylene: structure, properties and applications. Ed. E.C. Company - Texas, 2000.

20. RAMOS, M. A.; GIL, M.H.; SCHACHT, E.; MATTHYS, G.; MONDELAERS, W.; FIGUEIREDO, M.M.. Physical and chemical characterisation of some silicas and silica derivatives. Powder technology, v. 99 , n. 1 , p. $79-85,1998$.

21. RAMOS, V. M. Compósitos e nanocompósitos de polietileno de alta densidade-SiO2: Avaliação do tamanho de partícula e organofuncionalização de sílicas sobre as propriedades termomecânicas, reológicas e superficiais. Monografia (graduação em Engenharia Química) - UNISINOS. São Leopoldo, 2017.

22. SMITH, W. F.; HASHEMI, J. Fundamentos de engenharia e ciência dos materiais. 5. ed. Porto Alegre: McGraw-Hill, 2012.

23. TEIXEIRA, V. G.; COUTINHO, F. M. B; GOMES, A. S. Principais métodos de caracterização da porosidade de resinas à base de divinilbenzeno. Química Nova, v. 24, n. 6, p. 808-818, 2001.

24. VANSANT, E. F.; VOORT, R. V. D.; VRANCKEN, K.C. Characterization and chemical modification of the silica surface. 1. ed. Amsterdam: Elsevier Science B.V, 1995.

25. VENTURA, A. M. F. M. Os Compósitos e a sua aplicação na Reabilitação de Estruturas metálicas. Ciência \& Tecnologia dos Materiais, v. 21, n. 3-4, p. 10-19, 2009.

26. WUNDERLICH, B. Thermal Characterization of Polymer Materials; Turi, E. A., ed.; 2nd.ed., Academic Press Inc.: New York, 1997, vol. 1, p. 305.

27. ZHANG, M. Q. Mechanical Properties of Low Nano-Silica Filled High Density Polyethylene Composites. Polymer Engineering and Science, v. 43, n. 2, p. 490-500, 2003.

28. ZHURAVLEV, L. T. The surface chemistry of amorphous silica. Zhuravlev model. Colloids and Surfaces A: Physicochemical and Engineering Aspects, v. 173, n. 1, p. 1-38, 2000. 


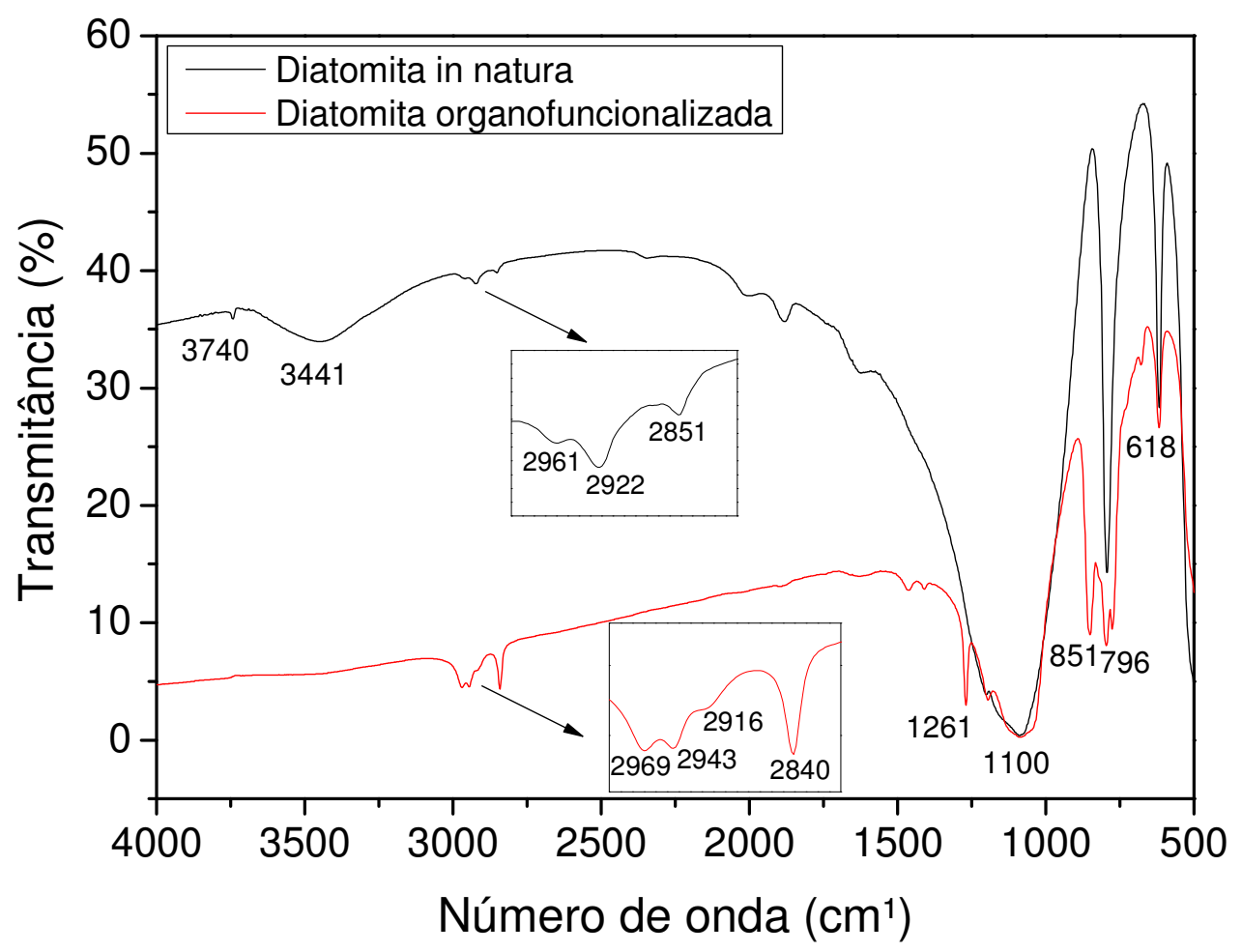

Figura 1. Espectros de FTIR da diatomita in natura e organofuncionalizada com metiltrimetoxisilano

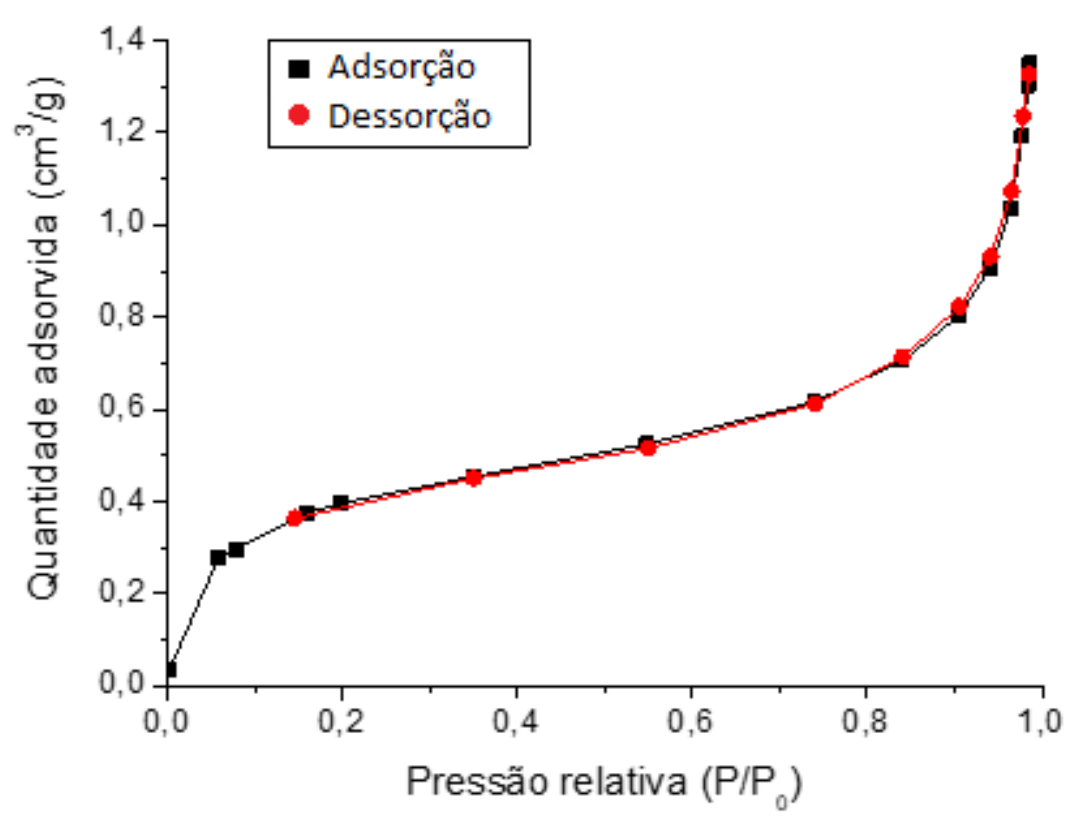

Figura 3.Isoterma de adsorção-dessorção de $\mathrm{N}_{2}$ para a diatomita in natura 


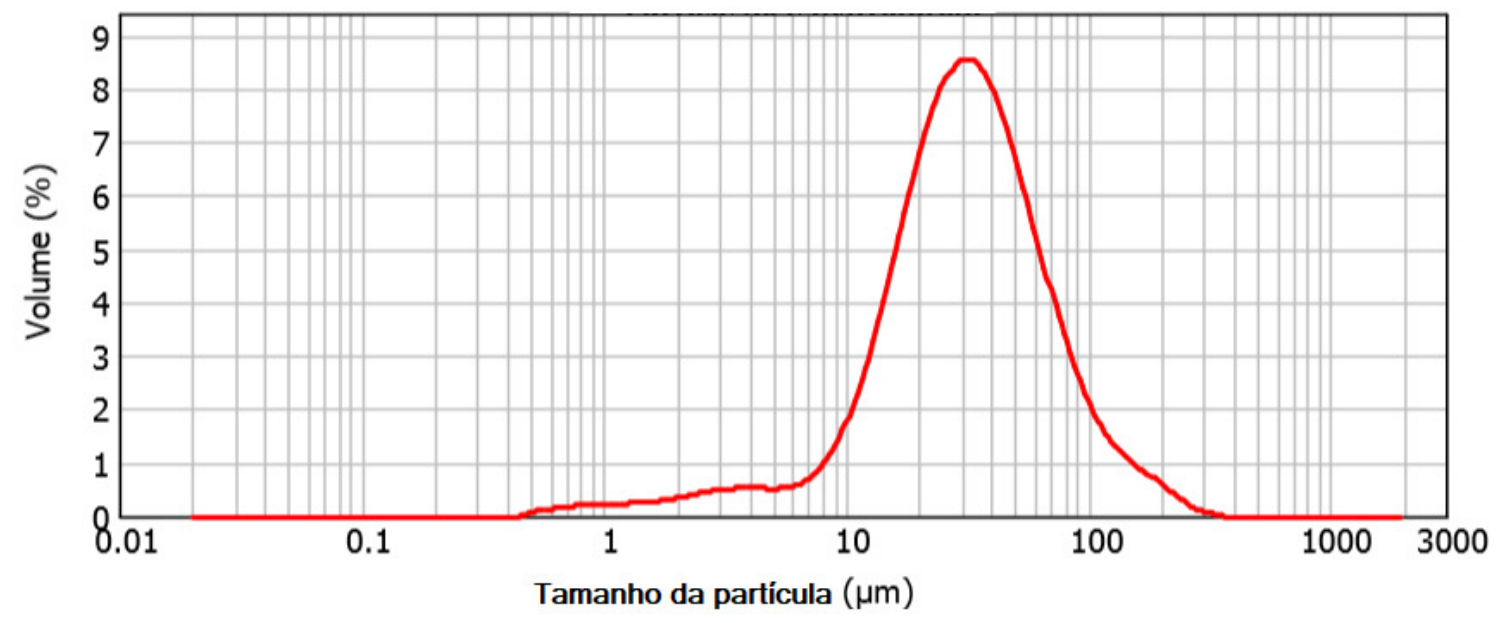

(a)

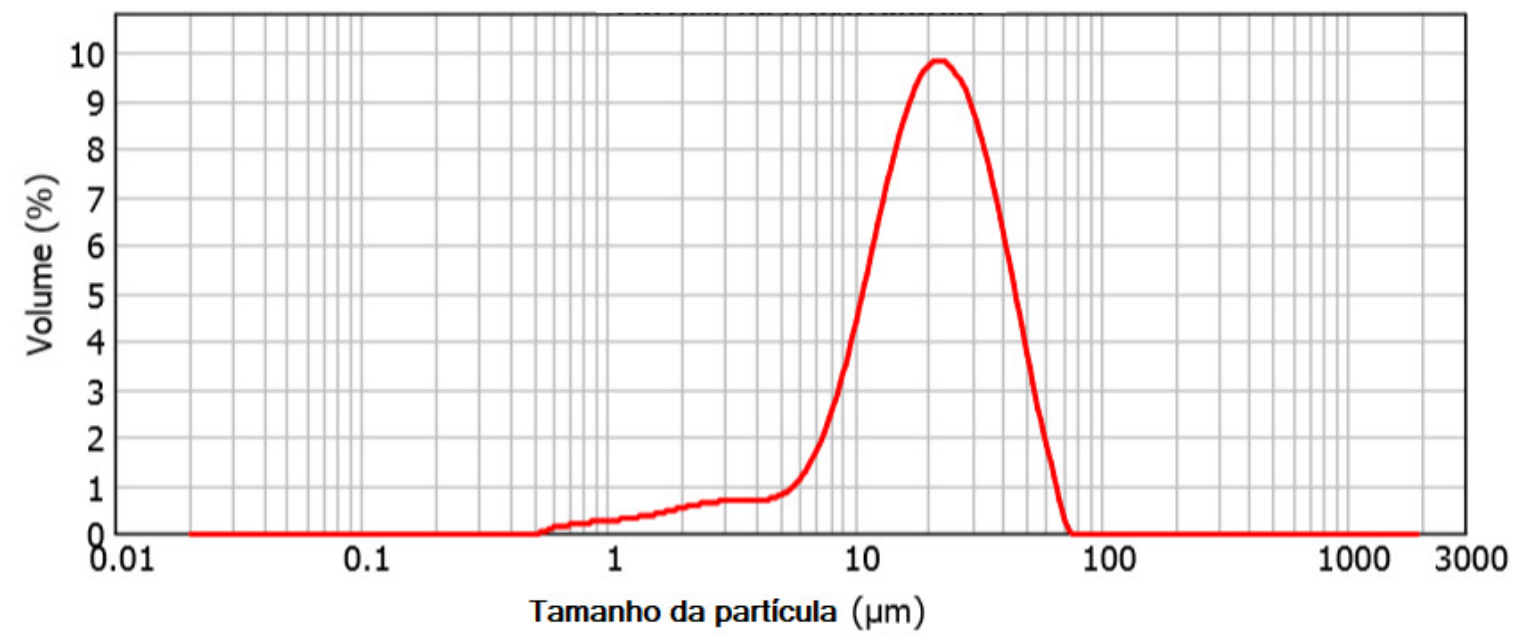

(b)

Figura 4.Curvas de distribuição de tamanho de partículas, obtidas pela técnica de granulometria de difração a laser: (a) diatomita in natura e (b) diatomita-C1 

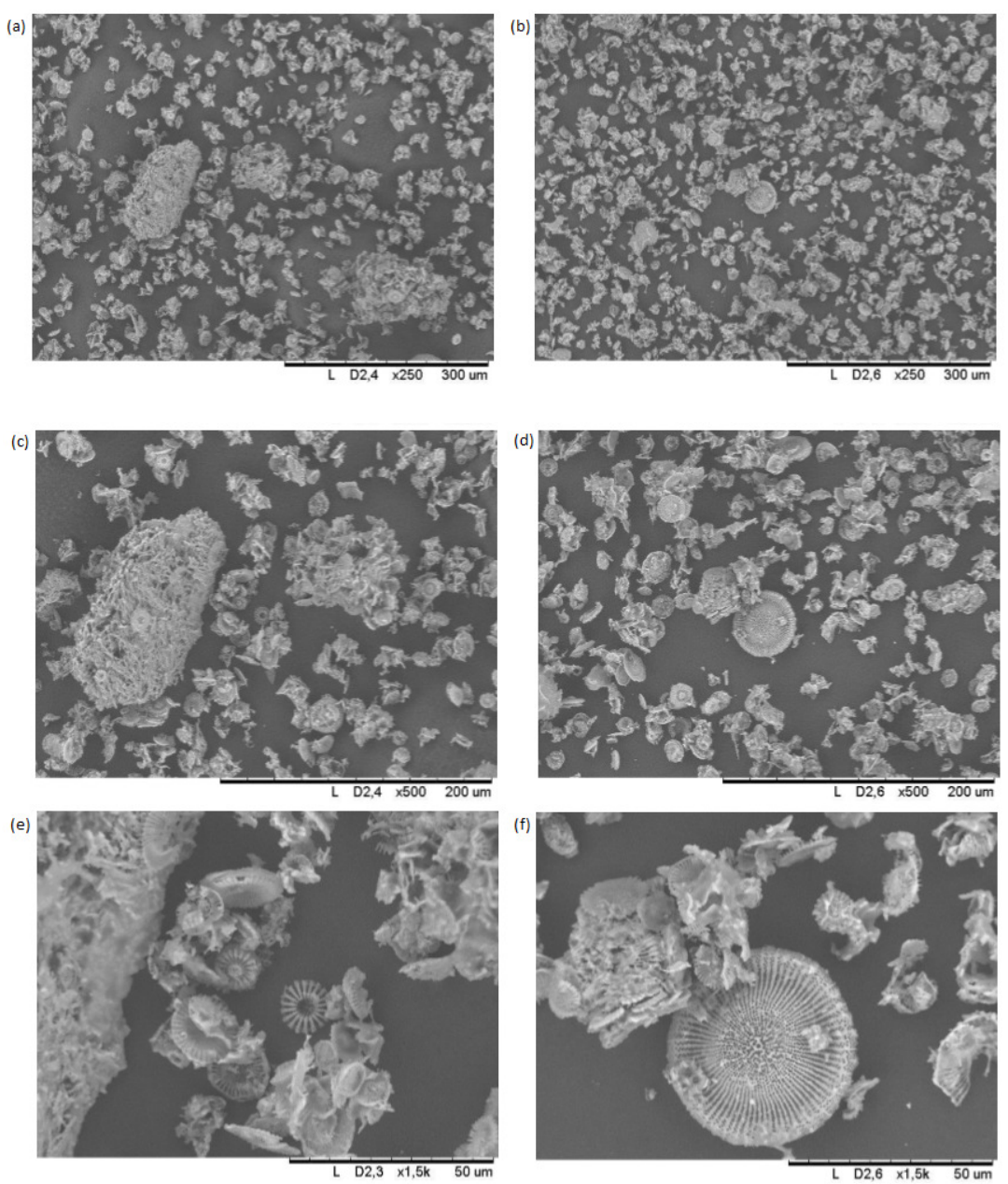

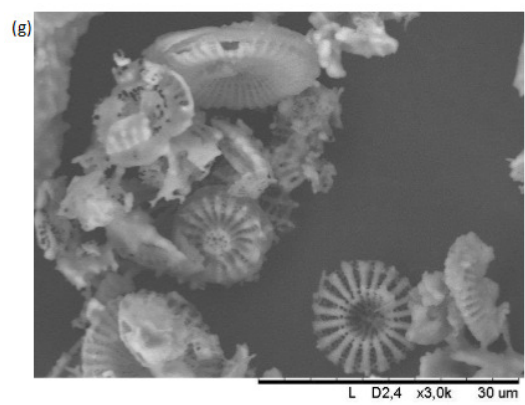

(a)

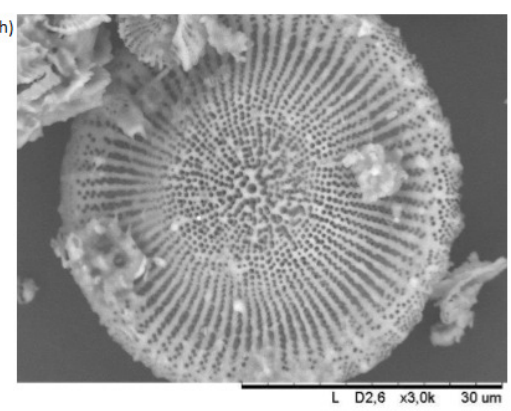

(b)

Figura 5.Micrografias de SEM das amostras: (a) diatomita in natura e (b) diatomita-C1 (Magnificações de 250, 500, 1500 e $3000 \times$ ) 


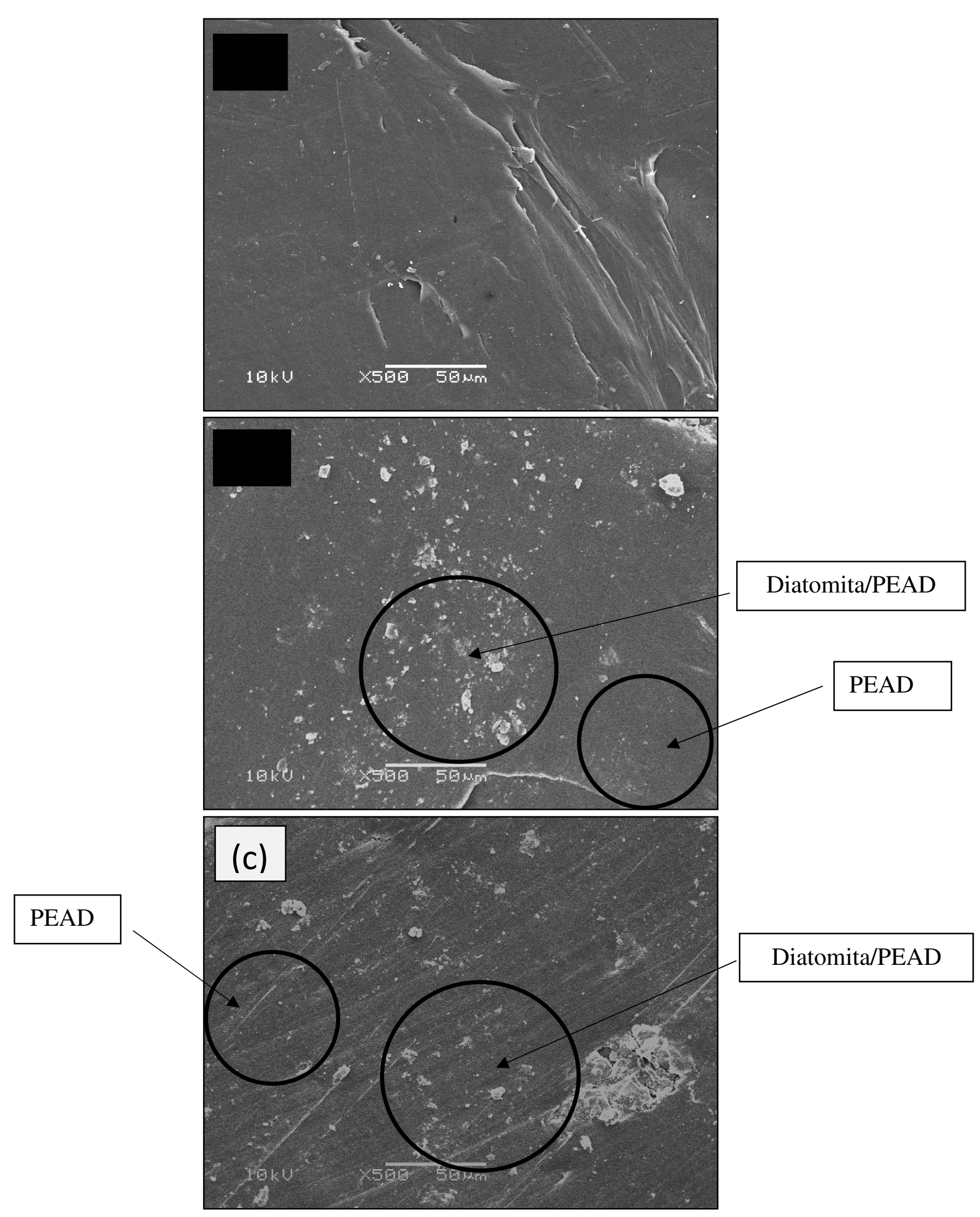

Figura 6.Micrografias de SEM das amostras: (a) PE; (b) PE-D2 e (c) PE-D5 (Magnificação de 500x) 


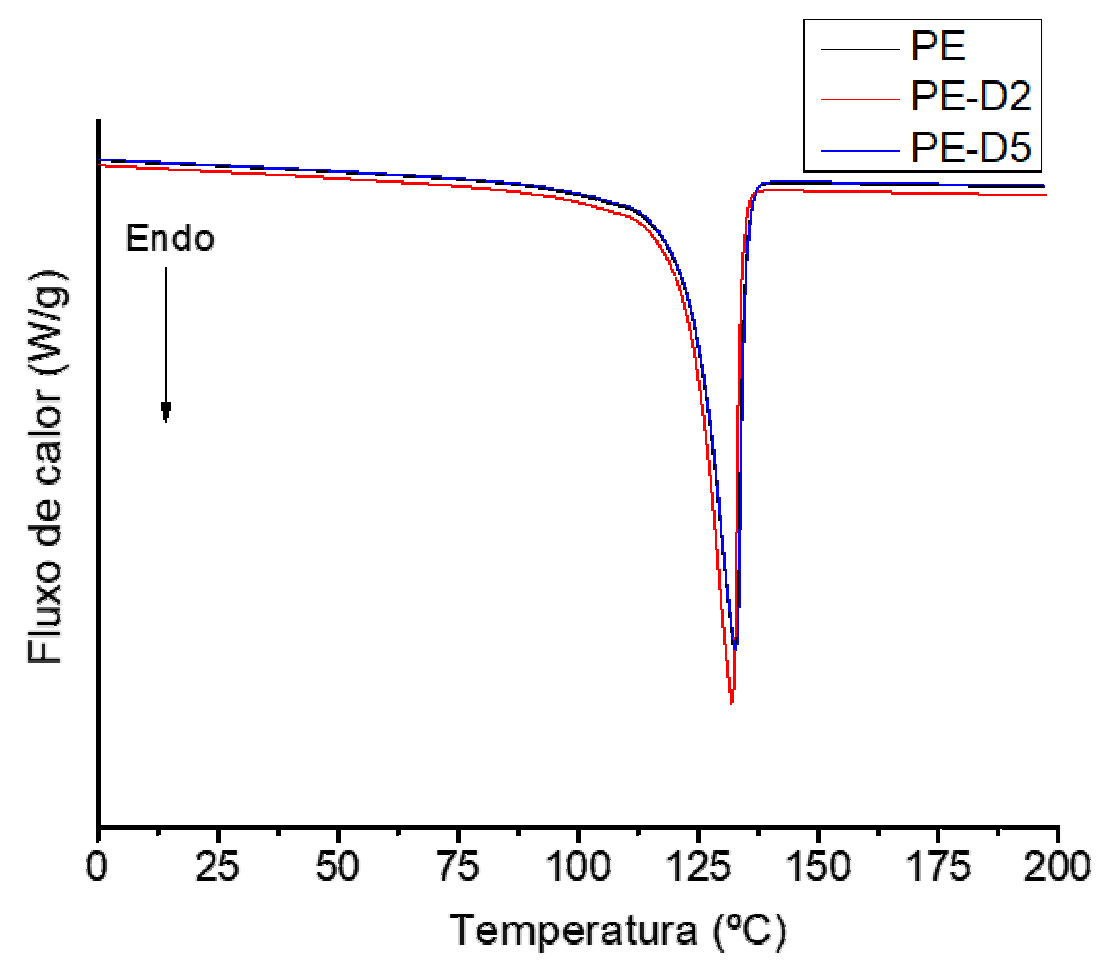

Figura 9. Curvas de DSC (segundo aquecimento) para PEAD e compósitos de $\mathrm{PEAD} /$ diatomita-C1

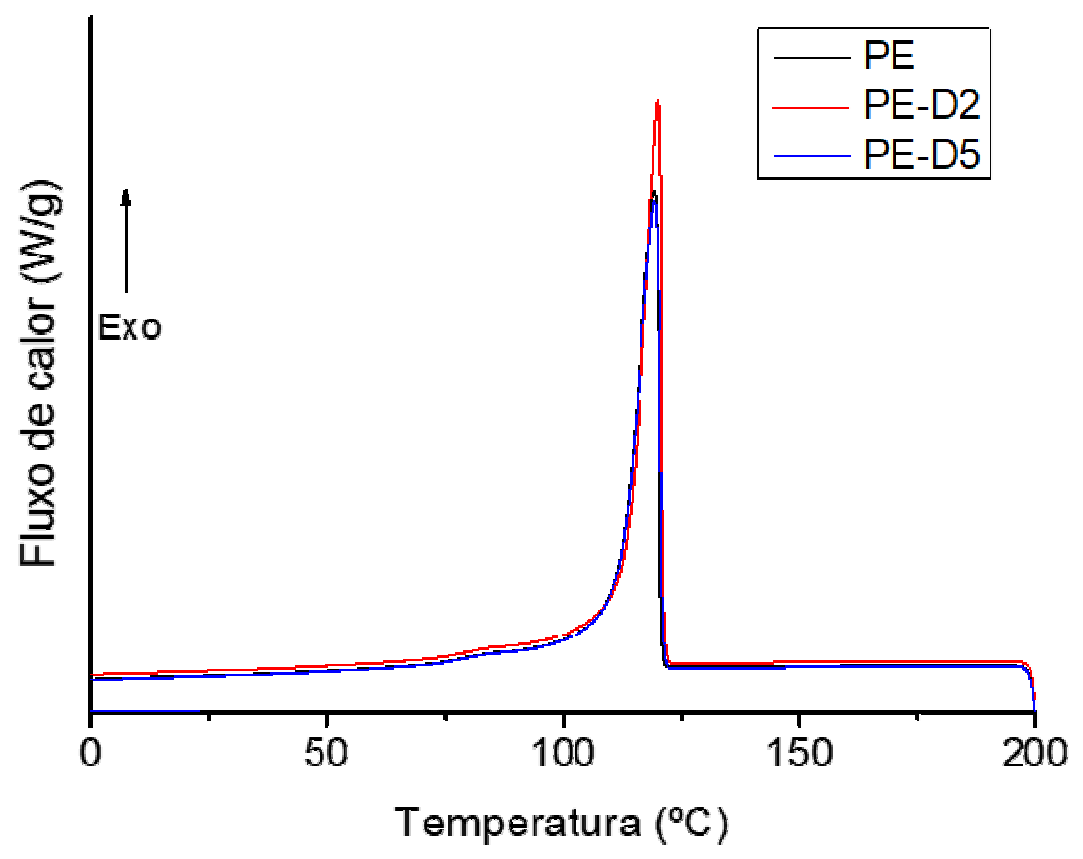

Figura 10. Curvas de DSC (resfriamento) para PEAD e compósitos de $\mathrm{PEAD/diatomita-C1}$

PERIÓDICO TCHÊ QUÍMICA•www.periodico.tchequimica.com• Vol. 16 N. 32.

- ISSN 1806-0374 (impresso) • ISSN 1806-9827 (CD-ROM) • ISSN 2179-0302 (meio eletrônico) (C) 2019. Porto Alegre, RS. Brasil

The Periódico Tchê Quimica (ISSN: 1806-0374; 2179-0302) is an open-access journal since 2004. Journal DOI: 10.52571/PTQ. http://www.tchequimica.com. This text was introduced in this file in 2021 for compliance reasons.

() The Author(s)

OPEN ACCESS. This article is licensed under a Creative Commons Attribution 4.0 (CC BY 4.0) International License, which permits use, sharing, adaptation, distribution, and reproduction in any medium or format, as long as you give appropriate credit to the original author(s) and the source, provide a link to the Creative Commons license, and indicate if changes were made. The images or other third-party material in this article are included regulation or exceeds the permitted use, you will need to obtain permission directly from the copyright holder. To view a copy of this license, visit http://creativecommons.org/licenses/by/4.0/. 